\title{
Sudden cardiac death in the young: cytokines and pathways
}

\author{
SHI-MIN YUAN \\ Department of Cardiothoracic Surgery \\ The First Hospital of Putian, Teaching Hospital, Fujian \\ Medical University \\ Putian 351100, Fujian Province \\ People's Republic of China

\section{Correspondence:} \\ Shi-Min Yuan \\ E-mail:shiminyuan@126.com \\ Key words: Apoptosis; Cardiac sudden death \\ Fas-associated death domain protein \\ Signal transduction.
}

Received May 12, 2016.

Revised January 17, 2017.

Accepted January 17, 2017.

\section{Abstract}

Background and Purpose: The underlying mechanisms of sudden cardiac death in terms of cytokines and pertinent signaling pathways have not been previously elaborated. The purpose of this paper is to clarify the cytokines and signaling pathways involved in the mechanisms of sudden cardiac death in the young.

Materials and Methods: Medical literature of sudden cardiac death in the young of recent decades were carefully collected as studying materials, and comprehensively reviewed and analyzed.

Results: Extrinsic and intrinsic apoptotic pathways, influenced by growth factor pathways, may render arrythmogenic cardiac disorders and ultimately lead to sudden cardiac death. Other cytokines probably involved in the mechanisms of sudden cardiac death in the young may include heme oxygenase-1 and the gaseous molecules (carbon monoxide and nitric oxide), insulin-like growth factor-1, gap junctional proteins and homeobox transcription factor NKX2-5, which may be responsible for atrioventricular conduction impairments. Active therapeutic options for the pertinent arrhythmias have significantly reduced the incidence of sudden cardiac death in the young. The apoptotic and growth factor signaling pathways are the two major ways leading to conduction system impairment and eventual sudden cardiac death.

Conclusions: The prophylactic antiarrhythmic agent, device therapies, or surgical operation could dramatically reduce sudden cardiac death incidence. Good understanding of the mechanisms of the cytokine-related pathways is crucial for the treatment of the causative cardiac disorders responsible for sudden cardiac death in the young. New agents including apoptotic blockers, heme metabolite homologues, and c-Src, PIK3 and NKX2-5 inhibitors, etc., are anticipated for the prevention of sudden cardiac death in the near future.

\section{INTRODUCTION}

Sudden cardiac death (SCD) is an unexpected death from cardiac Sevents, and occurs within one hour of onset of cardiac symptoms. In $25 \%$ of the cases, SCD occurred within 6 hours of physical activity (1). Preceding symptoms were reported in $35 \%$ of the cases prior to SCD. The symptoms can be circulatory (syncope, chest pain, dyspnea and palpitations), neurological (headache and visual disturbances), digestive, or institutional (e.g., recent febrile disease, usually a few days prior to SCD). It has been recognized that causes of SCD vary depending on age, gender, ethnicity and genetics (2). The incidence of SCD relies on population, of whom those in exercise are more likely vulnerable to SCD 


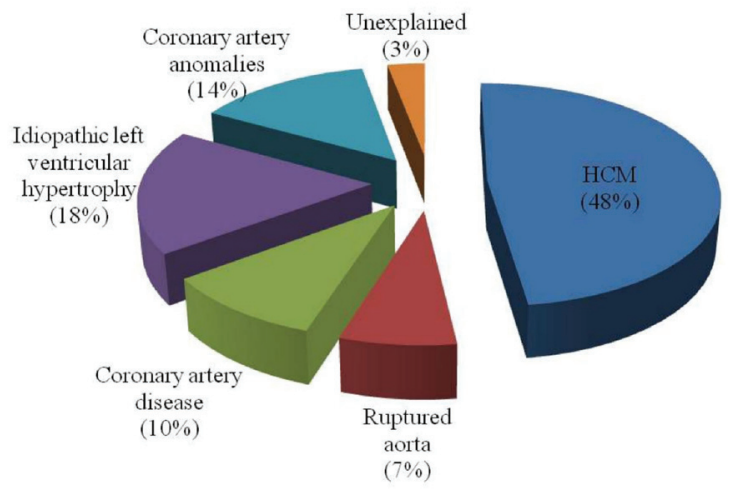

Figure 1. Distributions of causes of sudden cardiac death in the young athletes (11). HCM: hypertrophic cardiomyopathy.

(Table 1) (3-8). The incidence also varies on patients' gender, age and season: 2.3-fold higher in male than in female, increased with age, and highest in October and lowest in August (3). In a recent authoritative review, Ackerman et al. (9) made a summative assessment on the population-based estimates of SCD incidence in the young based on large medical centers from the world. The incidence differed depending on patient's age, hospitals and regions, but showed an overall range of 0.7-10.1 per 100,000 patient-years. However, the underlying mechanisms of SCDs in terms of cytokines and pertinent signaling pathways have not been previously elaborated. The
Table 1. Incidence of sudden cardiac death

\begin{tabular}{|lcc|}
\hline Population & $\begin{array}{c}\text { Incidence (per } \\
100,000 \text { person-year) }\end{array}$ & Reference \\
\hline General population & 0.0092 & $(3)$ \\
Young individuals & 2.28 & $(4)$ \\
$0-2$ years of age & 2.1 & $(4)$ \\
3-13 years of age & 0.61 & $(4)$ \\
$14-24$ years of age & 1.44 & $(4)$ \\
25-35 years of age & 4.40 & $(4)$ \\
Healthy men of exercise & 5.56 & $(5)$ \\
Joggers & 13.12 & $(6)$ \\
Basketball players & 32.26 & (7) \\
Young athletes (9-40 years) & $0.11-33.33$ & $(8)$ \\
\hline
\end{tabular}

purpose of this paper is to given a comprehensive review discussing the possible cytokine-related signaling pathways of SCDs in the young.

\section{ETIOLOGIES}

Berger (10) classified the etiological disorders for SCDs into structural or functional abnormalities, primary electrical abnormalities, acquired conditions and postopera-

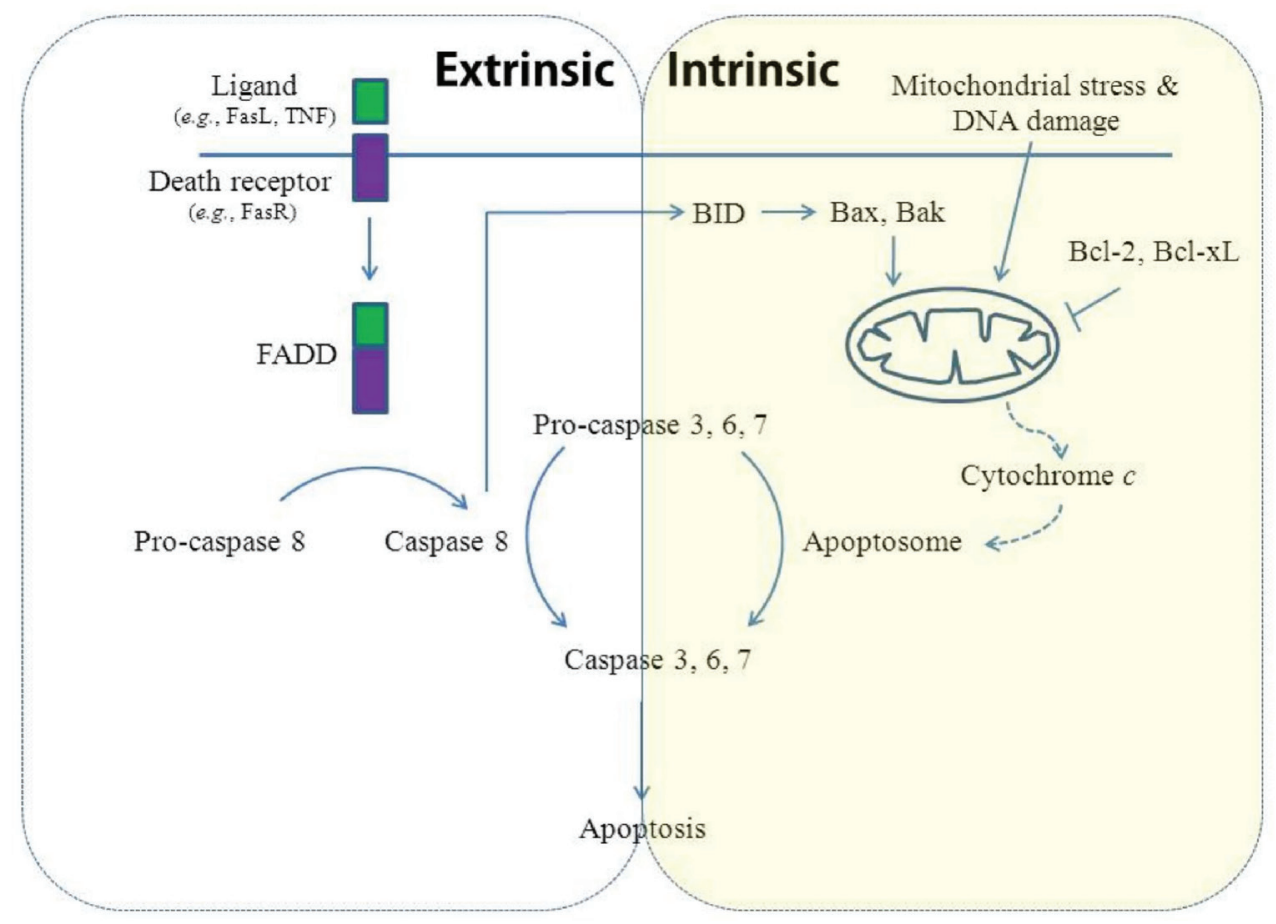

Figure 2. Apoptotic signaling pathways (17). The extrinsic pathway is triggered by a binding of a ligand and a death receptor and the intrinsic pathway is activated by mitochondrial stress leading to cytochrome $c$ release. By activating the initiator caspases and further the execution caspases, the apoptosis is initiated. Bak: Bcl-2 homologous antagonist/killer; Bax: BCL-2-associated X protein; Bcl-2: B-cell lymphoma 2; Bcl-xL: B-cell lymphoma-extra large; BID: Bcl-2 interacting protein; FADD: Fas-associated death domain; FasL: Fas ligand; TNF: tumor necrosis factor. 
Table 2. A summary of potential cytokines and pathways involved in the mechanisms of sudden cardiac death in the young

\begin{tabular}{|c|c|c|c|}
\hline Type of cytokines & Participating factors & Signaling pathways & Function \\
\hline Apoptotic regulator & $\begin{array}{l}\text { Tumor necrosis factor, anti-apoptotic } \\
\text { proteins (Fas-L \& Bcl-2) \& pro- } \\
\text { apoptotic proteins (Bak, Bax \& Bad) }\end{array}$ & Apoptosis signaling pathways & Triggering cardiac apoptosis \\
\hline Heme oxygenase & Heme oxygenase-1 & $\begin{array}{l}\text { p38 mitogen-activated protein kinase } \\
\text { (MAPK), phosphatidylinositol-3 } \\
\text { kinase (PI3K)/Akt pathway, } \\
\text { Jak-STAT pathway, toll-like receptor } \\
\text { (TLR)-4 pathway }\end{array}$ & $\begin{array}{l}\text { Inhibition of proinflammatory } \\
\text { cytokines \& chemokines }\end{array}$ \\
\hline $\begin{array}{l}\text { Insulin-like growth } \\
\text { factor (IGF)-1 }\end{array}$ & IGF-1 & IGF-1 signaling pathway & $\begin{array}{l}\text { Promotion of the cell proliferation } \& \\
\text { differentiation \& apoptosis inhibition }\end{array}$ \\
\hline $\begin{array}{l}\text { Cardiac gap } \\
\text { junctions }\end{array}$ & Connexins $40,43 \& 45$ & PI3K/Akt-mediated pathway & $\begin{array}{l}\text { Electrical impulse propagation } \& \\
\text { coordinated contraction of the heart, } \\
\text { maintenance } \& \text { modulation } \\
\text { of vascular tone }\end{array}$ \\
\hline $\begin{array}{l}\text { Vascular endothelial } \\
\text { growth factor }\end{array}$ & Vascular endothelial growth factor & $\begin{array}{l}\text { Vascular endothelial growth } \\
\text { factor signaling }\end{array}$ & $\begin{array}{l}\text { Promotion of mitosis of the vascular } \\
\text { endothelial cells \& angiogenesis }\end{array}$ \\
\hline NKX2-5 & NKX2-5 & Wnt signaling & Cardiomyogenesis \\
\hline $\begin{array}{l}\text { HF-1b zinc finger } \\
\text { protein }\end{array}$ & $\mathrm{HF}-1 \mathrm{~b}$ & Ras pathway & $\begin{array}{c}\text { A component of the endogenous } \\
\text { HF-1b/myocyte enhancer factor } \\
\text { (MEF) } 2 \text { binding activity in cardiac } \\
\text { muscle cells }\end{array}$ \\
\hline Heat shock proteins & Heat shock proteins & IGF-1 receptor signaling & $\begin{array}{c}\text { Suppression of apoptosis of } \\
\text { cardiomyocytes, suppression of } \\
\text { ubiquitination of IGF-1 receptor, } \\
\text { augmentation of IGF-1 receptor } \\
\text { signaling }\end{array}$ \\
\hline Heat shock factor 1 & Heat shock factor 1 & $\begin{array}{c}\text { Heat shock factor } 1 \text { signaling, IGF-1, } \\
\text { transforming growth factor- } \beta \text { \& cyclic } \\
\text { guanosine monophosphate (cGMP) } \\
\text { signaling }\end{array}$ & Protection against endotoxic shock \\
\hline Calcineurin & Calcineurin & Calcineurin signaling & $\begin{array}{l}\text { Activation of the local production of } \\
\text { nitric oxide by inducible nitric oxide } \\
\text { synthase in myocardiocytes }\end{array}$ \\
\hline
\end{tabular}

tive congenital heart disease. A representative review respectively proposed that hypertrophic cardiomyopathy is the most common cause of SCD in young athletes (Fig. 1) (11). Post-mortem analysis of cardiovascular pathology in SCD victims showed structurally normal heart in $27 \%$, coronary artery disease in $21 \%$ and hypertrophic cardiomyopathy in 15\% (12). Consensus revealed hypertrophic cardiomyopathy the most common, congenital coronary artery anomalies, myocarditis, dilated cardiomyopathy, Marfan's syndrome and arrhythmogenic right ventricular dysplasia (ARVD) the more common, and cardiac tumor, mitral valve prolapse, aortic valve stenosis, atherosclerotic coronary artery disease and long QT syndrome the lest common causes of SCDs in the young (13).

In infancy, the most common cause of death is congenital cardiac malformations. SCD may occur postoperatively in children with hypoplastic left heart syndrome between Norwood stage I and bidirectional Glenn procedures (14). The cause of SCD can be surgical technical problems, ventricular dysrhythmias, aspiration and altered baroreceptor reflexes, and electrical instability resulting from postoperative anatomical modifications. Majority of SCDs after repair of tetralogy of Fallot were due to ventricular arrhythmia, which could be screened by routine electrocardiogram (ECG) in whom SCDs occur later, and successful antiarrhythmic treatment could effectively prevent from SCDs (15).

Stenosis of the sinus node artery, which is frequent in patients younger than 40 years old as an important cause of SCD, is often associated with interstitial proliferation of the sinoatrial node. The etiologies of stenosis of the coronary orifice, an alternative common cause of SCD, include atheromatous plaque obstruction, syphilitic aortitis and congenital anomalies, with the latter one being less common than the previous two. Ion channelopathies represented by long QT, Brugada and Lev-Lenegre's syndromes with mutations of genes encoding sodium channels, as well as ventricular electrical storm characterized 
by critically malignant dysrhythmias due to extremely unstable electrical activities of the ventricle are also important causes of SCDs. In such patients, SCD has been evidenced histologically in the young victims by investigating the pathology of conduction system. A congenital abnormality of the His bundle, such as loop formation and fragmentation or displacement found in the pathological inspections was considered to be the cause of arrhythmogenic sudden death (16).

\section{CYTOKINES AND PATHWAYS}

Several potential cytokines and pathways that implicate in the pathogenesis of SCD in the young have been proposed. They are summarized in Table 2 . Their potential roles for further targeting are described below.

\section{Apoptotic regulators}

Apoptosis is a complex process of a programmed cell death that involves collapse of cell, protein degradation and deoxyribonucleic acid fragmentation. Unlike necrosis where the cells swell and soon disintegrate, thereby evoking an inflammatory response, apoptotic cells do not swell but actually shrink with extensive intracellular degeneration. Apoptosis may inevitably lead to electric instability of the myocardium and cause SCD. A close correlation between apoptotic rate and left ventricular remodeling has been noted. Tumor necrosis factor (TNF) mediates cardiac apoptosis by way of both the extrinsic and intrinsic pathways (Fig. 2) (17). The Fas-mediated apoptotic pathway is a major extrinsic pathway triggering cardiac apoptosis as a result of interactions between the cell surface death receptors (TNF receptor and Fas receptor) and extracellular ligands (TNF and Fas-L). The mitochondria-dependent apoptotic pathway releases apoptosisregulating proteins from the intermembrane, exemplified by the B-cell lymphoma 2 (Bcl-2) family, such as Bcl-2 homologous antagonist/killer (Bak), Bcl-2, Bcl-2-associated $\mathrm{X}$ protein (Bax) and $\mathrm{Bcl}-2$-associated death promoter (Bad). Immunohistochemical studies on SCD victim heart revealed a direct proportion between Fas-L, caspase 9 and Bax expression, indicating the role of apoptotic signal transduction mediated by Fas/Fas-L pathway in SCD (18). Experimental studies in transgenic mice ischemia-reperfusion model showed cardiac apoptosis could be inhibited by modification of apoptosis regulators and blockade of apoptosis executors. Moreover, extracellular signal-regulated kinases (ERK1/ERK2) and p38 mitogen-activated protein kinase (MAPK) pathways can be interacted with apoptosis pathways (19). The Janus kinase/ signal transducers and activators of transcription (JAK/ STAT) pathway was found to be closely related to inflammatory and apoptotic process. As a new downstream molecular target, it might regulate apoptosis and cell proliferation induced by deoxynivalenol (DON) and T-2 toxin. In turn, JAK/STAT pathway might be the activated by the phosphorylation of MAPK, the release of proinflammatory cytokines from the cells through binding to the cytokine receptor and activating the kinase JAK. In addition, the JAK/STAT pathway might also be involved in the cardiotrophin-1, a member of the interleukin- 6 family, and pressure overload-induced cardiomyopathy (20).

\section{Heme oxygenase (HO)}

$\mathrm{HO}$, isoformed by HO-1, HO-2 and HO-3, is responsible for the physiological breakdown of heme into equimolar amounts of biliverdin, carbon monoxide $(\mathrm{CO})$ and iron. $\mathrm{HO}-1$ is ubiquitous and its messenger ribonucleic acid (mRNA) can be overexpressed by several folds in the presence of heme, other metalloporphyrins, transition metals and stress. HO-2 is present chiefly in the brain and testes and is virtually uninducible. HO-3 has very low enzyme activity. In isolated rat heart ischemia-reperfusion model, a significant reduction of $\mathrm{HO}$-related $\mathrm{CO}$ production was noted to be associated with reperfused ventricular fibrillation (VF), indicating the important arrhythmogenic role of the endogenous CO (21). Experimentally, zinc protoporphyrin IX (Zn-PPIX) $(5 \mathrm{mM})$ treatment caused downregulation of HO-1 mRNA and a reduction of $\mathrm{HO}$ activity in VF hearts (22).

HO-1 overexpression inhibits proinflammatory cytokines and chemokines under hypoxia, alleviates cardiomyocyte apoptosis and regulating pathological left ventricular remodeling (23). The anti-inflammatory properties of HO-1 may rely on its ability to degrade heme and generate bilirubin, free iron and $\mathrm{CO}$, and to reverse IL-18-mediated $\mathrm{p} 38 \alpha \mathrm{MAPK}$ and nuclear factor- $\mathrm{KB}$ activation, phosphatase and tensin homolog (PTEN) induction, Akt suppression and endothelial cell death (24). HO-1 mRNA upregulation prevents from reperfused VF by promoting endogenous $\mathrm{CO}$ formation (21). Genetic missense mutation in cardiac potassium- and calciumchannel proteins might be responsible for SCD from ventricular arrhythmias.

The nuclear factor-erythroid (NF-E) 2-related factor 2 (Nrf2) is a positive regulator of $\mathrm{HO}-1$ gene induction (25). It is involved in protection against oxidant stress in cardiovascular diseases, such as atherosclerosis, hypertension, heart failure and ischemia-reperfusion injury as well as aging. Alam et al. (25) have provided substantial evidence that overexpression of $\mathrm{Nrf} 2 \mathrm{M}$, a mutant of $\mathrm{Nrf2}$, inhibits HO-1 mRNA accumulation in response to heme, zinc, cadmium and arsenic. Under conditions of $\mathrm{Nrf2M}$ overexpression, HO-1 mRNA accumulation in response to heme, cadmium, zinc, arsenite and tert-butylhydroquinone was inhibited.

\section{Insulin-like growth factor-1 (IGF-1)}

IGF-1 displays multiple biological functions including promotion of the cell proliferation and differentiation and apoptosis inhibition by regulating gene expressions of the 
myocytes. IGF-1 upregulates the phosphorylation levels of the Akt protein of the heart. LY294002, a specific inhibitor of the phosphatidylinositol 3-kinase (PI3K), not only reduces the level of Akt phosphorylation induced by IGF-1 itself, but also reverses IGF-1, promotes the functional recovery of the cryopreserved heart, thereby playing an important anti-apoptotic role (26). Cardioprotective effects of IGF-1 against apoptosis are present through inhibition of apoptotic inducers, by upregulation of the renin-angiotensin system, or by downregulation of Kruppel-like factor 9, which further downregulates cytochrome P450, a member of the cytochrome $c$ family (27). IGF-1 partly recovers mitochondrial function of the myocytes through downregulation of cytochrome $c$ gene expression induced by hydrogen peroxide through downregulation of $r K L F 9$ gene expressions. IGF-1 may exert dual effects, either protective or harmful, on cardiomyoytes and on the vascular wall depending on whether the vascular endothelium is intact or impaired. Chisalita et al. (28) reported that the IGF-1 level was significantly higher in patients with heart failure or ischemic heart disease with angiotensin converting enzyme-inhibitor than those without $(103.4 \pm 39.7 \mu \mathrm{g} / \mathrm{L} v s .84 .4 \pm 30.0 \mu \mathrm{g} / \mathrm{L}$, $p=0.02$ ). By contrast, Boquist et al. (29) offered a divergent concept that fasting serum free IGF-1 correlated inversely with atherosclerosis-associated events based on a study on 96 healthy subjects.

\section{Gap junctional proteins}

The gap junctional channels are formed from connexins (Cx'es), responsible for electrical impulse propagation and coordinated contraction of the heart. Altered gap junction distribution and function may lead to disturbed cardiac rhythmicity, including reentry. The human cardiomyocytes express three different types of gap junction subunits: Cx43, Cx40 and Cx45 (30). Gap junction $\alpha-1$ protein, also known as $\mathrm{Cx} 43$, is a major gap junction protein maintaining normal electrical conduction in the heart. In Cx43-deficient mice, a 30-44\% reduction of ventricular conduction velocity and prolongation of the QRS waves were observed (31). Cx gene deletion adversely affected the conduction system to a moderate degree as proved by the experiments in the heterozygous $\mathrm{Cx} 40$ and Cx43 knock-out mice. Cx43 conditional knockout mice with induced deletion of $\mathrm{Cx} 43$ in the heart exhibited reduced conduction velocity, increased dispersion of conduction, and enhanced electrical vulnerability on the ventricular level (32). Experimental studies revealed that $\mathrm{Cx} 45$ could be a substitute of $\mathrm{Cx} 40$ when the latter was deficient in the atrioventricular node, at least partly identifying the compensating properties of various $\mathrm{Cx}$ proteins (33). In 156 probands with progressive familial heart block type I, a novel germ line heterozygous missense mutation in exon 2 of the Cx40 gene GJA5 was identified, whereas mutations were not found in connexin genes GJA1 (Cx43) or GJC1 (Cx45). Increased Cx43 mRNA and protein may lead to enhanced dye permeability and propagation of calcium (34).

Gap junction protein expression or functional alteration may implicate an arrhythmogenic substrate in hypertrophic, ischemic, or dilated cardiomyopathies. Downregulation of $\mathrm{Cx} 43$ was observed in the ventricle of patients with hypertrophic, dilated and ischemic cardiomyopathies. Increased heterogeneity of $\mathrm{Cx} 43$ was found in both patients with congestive heart failure and documented ventricular tachycardias and the heart failure mouse model that showed inducible polymorphic ventricular tachycardia in the setting of heterogeneous $\mathrm{Cx} 43$ loss. $\mathrm{Cx} 43$ is a plausible candidate gene for premature sudden death and a Cx43 mutation is a pathogenic substrate for sudden infant death syndrome. Right ventricular endomyocardial biopsy in ARVD patients showed a significant reduced Cx40 mRNA and Cx45 mRNA expressions. Therefore, loss of gap junctions and shifted composition of gap junction channels of the conduction system might contribute to the development of ventricular arrhythmias in patients with ARVD (35).

\section{Vascular endothelial growth factor (VEGF)}

VEGF is a strong and specific cytokine that promotes mitosis of the vascular endothelial cells and angiogenesis. When subjected to hypoxia or ischemia, especially in the myocytes adjacent to the myocardial infarct area, the VEGF expressions are upregulated in the local tissues, probably due to the angiogenesis in that area (36). The patchy immunohistochemical positivity of hypoxia-inducible factor-1 $\alpha$, erythropoietin and VEGF in cardiomyocytes in the acute myocardial infarction and sporadic positivity in cardiomyocytes of SCD case without infarction indicate a proportion between the expressions and the structure damage of cardiomyocytes (37).

\section{NKX2-5 and HF-1b}

NKX2-5 and HF-1b implicate in conduction system development and disease. Several candidate molecules, including homeobox transcription factor NKX2-5, are related to SCD due to the resultant impaired conduction system, for example, in the context of gene mutations. HF- $1 \mathrm{~b}$ is a transcriptional factor preferentially expressed in the cardiac conduction system and ventricular myocytes. HF-1b-deficient mice in associated with Cx40 redistribution predisposes to conduction system impairment, subsequent malignant lethal arrhythmia and sudden death (38).

\section{Heat shock proteins (HSPs) and calcineurin}

HSPs confer protection against cardiovascular disease. Heat shock transcription factor (HSF) 1 is one of the transcription factors that regulate the expression of HSPs. 
HSF1 is repressed by GSK-3 $\beta$ (Ser303), ERK (Ser307) and JNK (Ser363) under normal conditions; whereas, it is activated by hyperphosphorylation (Ser-230) upon exposure to different stressors. HSFs including HO-1 provide significant protection against a variety of chemical and physical tissue damages associated with excessive production of reactive oxygen species. In the heart of transgenic mice with HSF1 or inducible HSP70 overexpressions, more resistance to ischemia-reperfusion injury was shown in compared with wildtype mice. In addition, HSPs may also protect against myocardial infarction and doxorubicin-induced cardiomyopathy (39). HSP90 was remarkably decreased in the tissues of hypertrophic cardiomyopathy pigs of sudden death, but not in the tissues of non-hypertrophic cardiomyopathy or normal pigs. Calcineurin, a protein phosphatase also known as protein phosphatase 3 , and calcium-dependent serine-threonine phosphatase, activates the local production of NO by inducible NO synthase in cardiac myocytes. Overexpression of calcineurin significantly contributes to sudden death, heart block, left ventricular dilation and impaired systolic performance of the ventricle (40).

\section{MANAGEMENT}

\section{Screening investigations}

In order to predict any potential SCDs, US Preventive Services Task Force proposed an analytic framework for screening including descriptive epidemiology and etiology, screening methodology and optimal management. Of importance, ECG may reveal the causative cardiovascular diseases responsible for $\mathrm{SCD}$, such as cardiomyopathies, channelopathies and cardiac conduction system diseases. Resting ECG serves as an adjunctive for disclosing heart block of any degree or early repolarization syndrome; while stress ECG, for induced symptoms including chest pain, ischemic ECG changes, conduction abnormalities and early repolarization during the exercise test; and echocardiogram, for cardiac structural or functional abnormalities. Family evaluation and genetic testing are also helpful in the early warning of SCDs (41).

\section{Conservative treatment}

Timely diagnosis of the underlying cardiovascular diseases, prohibition of high intensity exercise, pharmacotherapy and other treatments help to prevent SCDs in the affected athletes. In the event of ventricular electrical storm, electric defibrillation and cardioversion should be performed as soon as possible for hemodynamic stabilization. Current views support that $\beta$-blockers (metoprolol is preferred) is the drug of first choice, which is followed by amiodarone or sotalol, and a combination of both if necessary. As mitochondrial damage and Bcl-2-to-Bax balance play a central role in ischemia-dependent apoptosis while angiotensin II and $\beta_{1}$-adrenergic-stimulation may be the major causes of receptor-mediated apoptosis, treatment with angiotensin-converting enzyme inhibitors and $\beta$-blockers could reduce myocardial apoptosis (42). Quinidine and isoproterenol are effective for the electrical storm of Brugada syndrome. In other genetic arrhythmias, such as idiopathic long QT syndrome or short QT syndrome, $\beta$-blockers, quinidine and isoproterenol, etc., still have their places. c-Src inhibitor, such as 1-(1,1-dimethylethyl)-1-(4-methylphenyl)-1H-pyrazolo(3,4-d) pyrimidin-4-amine (PP1), reduces c-Src and raises Cx43 levels. Cx43 upregulation occurs primarily at the intercalated disks and correlates with gap junction functional improvement, and associated with a reduced risk of ventricular tachycardia inducibility and SCD. The activation of renin-angiotensin system is associated with c-Src upregulation, $\mathrm{Cx} 43$ loss, reduced myocyte coupling and arrhythmic sudden death (43).

\section{Interventional therapy}

Transcutaneous cardiac pacing may be considered in the patients with bradycardia and asystole. Radiofrequency ablation is indicated for abnormal electrical pathway arrhythmias including bundle-branch block and ventricular tachycardia. However, implantable cardioverter defibrillator (ICD) is indicated in those with SCD and there are growing evidences showing the additional benefit of radiofrequency ablation in treating ventricular arrhythmia and electrical storm. Prophylactic cardioverter defibrillator therapy in patients at high risk of SCD has been attempted, and the annual SCD rate has been reduced dramatically (44).

Catheter ablation is a possible alternative to decrease the incidence of ICD therapy and is useful especially during electrical storm after ICD implantation. Successful catheter ablation of focal VF and VF storm targeting Purkinje-like potentials in patients with non-ischemic dilated cardiomyopathy has been performed (45).

\section{Cardiac surgery}

Cardiac surgery can be a primary treatment for SCD. $S C D$ in patients with anomalous origin of coronary artery is associated with the anatomical features including abnormal coursing, acute angle take-off and ostial abnormalities. Surgical treatment is a definitive therapy. However, simple coronary artery bypass grafting is not recommended due to the potential hazards of coronary steal phenomenon and poor patency of the mammary arterial grafts. Nevertheless, modified maneuvers, such as coronary ostial reimplantation, impinged coronary segment unroofing and coronary stent deployment, are advocated instead (46). Surgical treatment of ventricular arrhythmias includes excision of ventricular tachycardia foci and excision of left ventricular aneurysms. Aortic valve replacement and mitral valve repair or replacement, associated with improved outcome of patients with hemo- 
dynamically significant valvular stenosis and well-preserved ventricular function. Orthotopic heart transplantation is indicated in patients with pending SCD and refractory heart failure with expected survival improvement. Patients with long QT syndrome who do not respond to $\beta$-blockers are candidates for ICD implantation or high thoracic left sympathectomy (44).

\section{DISCUSSION}

Ventricular arrhythmogenesis has been regarded as the main pathophysiological provocateur of SCD. The heterogeneous structural and functional conduction system impairments that disrupt the normal propagation of action potentials through the ventricles initiated by certain cytokine-related pathways predisposes to the impulses around an anatomic barrier in ischemic or scarred myocardium, or around a reentry in non-ischemic or structurally normal myocardium. Three general mechanisms of arrhythmia in genetic conditions predisposing to SCD have been known as abnormal repolarization (long QT syndrome, short QT syndrome and Brugada syndrome), slow ventricular conduction (Brugada syndrome) and aberrant intracellular calcium homeostasis (catecholaminergic polymorphic ventricular tachycardia). Molecular and genetic mechanisms interfering the NADH/NAD ${ }^{+}$ imbalance, protein kinase $\mathrm{C}$ activation and phosphorylation of a specific serine residue (Ser1503) on NaV1.5 and mutations of the ion channel genes have been illustrated. More broad research in this regard is warranted.

The autonomic nervous system serves as to modulate cardiac electrophysiology and arrhythmogenesis. In inherited arrhythmia disorders, sympathetic stimulation implicates in ventricular tachyarrhythmias and SCDs. In the animals susceptible to sudden death, modulation of the autonomic tone may increase cardiac vagal activity and reduce the risk for VF and SCDs (47).

Inflammatory arrhythmogenic mechanisms of proinflammatory cytokines have been received much attention. Inflammation links to various pathological processes, such as oxidative stress, apoptosis, fibrosis and arrhythmic substrate formation in the presence of endothelial dysfunction, platelet activation and coagulation cascade activation. Increased TNF- $\alpha$, interleukin- 6 and interleukin-4 levels was associated with more ventricular arrhythmias. Myocarditis, the actual inflammation of myocardium, represents a frequent cause of life-threatening ventricular arrhythmias and sudden death possibly through a modulation of ion channel function, mainly potassium and calcium channels in both viral and autoimmune myocarditis (48). Gap junctions are critical for maintaining synchronized impulse propagation and repolarization. Heterogeneous expression of the principal ventricular gap junction protein Cx43 is associated with action potential duration dispersion across the anterior ventricular wall (49). The Cx-containing channels are completely inactivated under inflammatory conditions, and the subsequent transmural electrophysiological heterogeneity of the left ventricle contributes to the underlying arrhythmia susceptibility (49). Treatment with probucol by its antioxidant and/or antiinflammatory effects effectively attenuated left ventricular dysfunction and remodeling in tachycardia-induced heart failure model (50).

\section{CONCLUSIONS}

The mechanisms of SCD are complex, and all might ultimately be attributed to their arrthmogenic property. Apoptotic and growth factor signaling pathways are the two major ways that the cytokines follow, in a common sense, with the gaseous molecules CO and NO involved, leading to conduction system impairment and eventually SCDs. The prophylactic antiarrhythmic agent or device therapy could reduce SCD incidence dramatically. Good understanding of the mechanisms of these cytokine-related pathways is crucial for the prevention and treatment of the causative cardiac disorders. New agents including apoptotic blockers, heme metabolite homologues, and cSrc, PIK3 and NKX2-5 inhibitors, etc., are highly anticipated in the prevention of SCDs in the near future.

\section{REFERENCES}

1. AMITAL H, GLIKSON M, BURSTEIN M, AFEK A, SINNREICH R, WEISS Y, ISRAELI V 2004 Clinical characteristics of unexpected death among young enlisted military personnel: results of a three-decade retrospective surveillance. Chest. 126: 528-33 https://doi.org/10.1378/chest.126.2.528

2. SUNG RJ, KUO CT, WU SN, LAI WT, LUQMAN N, CHAN NY 2008 Sudden cardiac death syndrome: age, gender, ethnicity, and genetics. Acta Cardiol Sin. 24: 65-74

3. STRAUS SM, BLEUMINK GS, DIELEMAN JP, VAN DER LEI J, STRICKER BH, STURKENBOOM MC 2004 The incidence of sudden cardiac death in the general population. J Clin Epidemiol. 57: 98-102 https://doi.org/10.1016/S0895-4356(03)00210-5

4. MEYER L, STUBBS B, FAHRENBRUCH C, MAEDA C, HARMON K, EISENBERG M, DREZNER J 2012 Incidence, causes, and survival trends from cardiovascular-related sudden cardiac arrest in children and young adults 0 to 35 years of age: a 30-year review. Circulation; 126: 1363-72 https://doi.org/10.1161/CIRCULATIONAHA.111.076810

5. SISCOVICK DS, WEISS NS, FLETCHER RH, LASKY T 1984 The incidence of primary cardiac arrest during vigorous exercise. N Engl J Med 311: 874-7 https://doi.org/10.1056/NEJM198410043111402

6. THOMPSON PD, FUNK EJ, CARLETON RA, STURNER WQ 1982 Incidence of death during jogging in Rhode Island from 1975 through 1980. JAMA 247: 2535-8 https://doi.org/10.1001/jama.1982.03320430039028

7. HARMON KG, ASIF IM, KLOSSNER D, DREZNER JA 2011 Incidence of sudden cardiac death in National Collegiate Athletic Association athletes. Circulation 123: 1594-600 https://doi.org/10.1161/CIRCULATIONAHA.110.004622

8. HARMON KG, DREZNER JA, WILSON MG, SHARMA S 2014 Incidence of sudden cardiac death in athletes: a state-of-theart review. Br J Sports Med 48: 1185-92 https://doi.org/10.1136/bjsports-2014-093872 
9. ACKERMAN M, ATKINS DL, TRIEDMAN JK 2016 Sudden cardiac death in the young. Circulation 133: 1006-26 https://doi.org/10.1161/CIRCULATIONAHA.115.020254

10. BERGER S, KUGLER JD, THOMAS JA, FRIEDBERG DZ 2004 Sudden cardiac death in children and adolescents: introduction and overview. Pediatr Clin North Am 51: 1201-9 https://doi.org/10.1016/j.pcl.2004.04.008

11. MARON BJ, EPSTEIN SE, ROBERTS WC 1986 Causes of sudden death in competitive athletes. J Am Coll Cardiol 7: 204-14 https://oi.org/10.1016/S0735-1097(86)80283-2

12. CHUGH SS 2011 Approach to unexplained sudden death in the young: proactive during life and prospective at death. Europace 13: 1364-5 https://doi.org/10.1093/europace/eur265

13. MARON BJ, PELLICCIA A, SPIRITO P 1995 Cardiac disease in young trained athletes. Insights into methods for distinguishing athlete's heart from structural heart disease, with particular emphasis on hypertrophic cardiomyopathy. Circulation 91: 1596-601 https://doi.org/10.1161/01.CIR.91.5.1596

14. MAHLE WT, SPRAY TL, GAYNOR JW, CLARK BJ $3^{\text {rd }} 2001$ Unexpected death after reconstructive surgery for hypoplastic left heart syndrome. Ann Thorac Surg 71: 61-5 https://doi.org/10.1016/S0003-4975(00)02324-9

15. GARSON A JR, RANDALL DC, GILLETTE PC, SMITH RT, MOAK JP, MCVEY P, et al. 1985 Prevention of sudden death after repair of tetralogy of Fallot: treatment of ventricular arrhythmias. J Am Coll Cardiol 6: 221-7

https://doi.org/10.1016/S0735-1097(85)80279-5

16. BHARATI S, LEV M 1986 Congenital abnormalities of the conduction system in sudden death in young adults. J Am Coll Cardiol 8: 1096-104 https://doi.org/10.1016/S0735-1097(86)80387-4

17. MCILWAIN DR, BERGER T, MAK TW 2013 Caspase functions in cell death and disease. Cold Spring Harb Perspect Biol 5: a008656 https://doi.org/10.1101/cshperspect.a008656

18. CEAUSU M, CURCĂ C, ARDELEANU C, DERMENGIU D 2008 Immunophenotypical pleomorphism expression in sudden cardiac death. Rom J Morphol Embryol 49: 315-20

19. ZHAO H. Extrinsic and intrinsic apoptosis signal pathway review. http://www.intechopen.com/books/apoptosis-and-medicine/extrinsic-and-intrinsic-apopto sis-signal-pathway-review. Accessed on April 2015.

20. TAKANO H, ZOU Y, AKAZAWA H, TOKO H, MIZUKAMI $\mathrm{M}$, HASEGAWA $\mathrm{H}$, et al. 2002 Inhibitory molecules in signal transduction pathways of cardiac hypertrophy. Hypertens Res 25: 491-498 https://doi.org/10.1291/hypres.25.491

21. BAK I, PAPP G, TUROCZI T, VARGA E, SZENDREI L, VECSERNYES M, et al. 2002 The role of heme oxygenase-related carbon monoxide and ventricular fibrillation in ischemic/reperfused hearts. Free Radic Biol Med 33: 639-48 https://doi.org/10.1016/S0891-5849(02)00913-9

22. CSONKA C, VARGA E, KOVACS P, FERDINANDY P, BLASIG IE, SZILVASSY Z, et al. 1999 Heme oxygenase and cardiac function in ischemic/reperfused rat hearts. Free Radic Biol Med 27: 119-26 https://doi.org/10.1016/S0891-5849(99)00077-5

23. WANG G, HAMID T, KEITH RJ, ZHOU G, PARTRIDGE CR, XIANG X, et al. 2010 Cardioprotective and antiapoptotic effects of heme oxygenase-1 in the failing heart. Circulation 121: 1912-25 https://doi.org/10.1161/CIRCULATIONAHA.109.905471

24. ZABALGOITIA M, COLSTON JT, REDDY SV, HOLT JW, REGAN RF, STEC DE, et al. 2008 Carbon monoxide donors or heme oxygenase-1 (HO-1) overexpression blocks interleukin-18mediated NF-кB-PTEN-dependent human cardiac endothelial cell death. Free Radic Biol Med 44: 284-98 https://doi.org/10.1016/j.freeradbiomed.2007.08.012

25. ALAM J, STEWART D, TOUCHARD C, BOINAPALLY S, CHOI AM, COOK JL 1999 Nrf2, a Cap'n'Collar transcription factor, regulates induction of the heme oxygenase-1 gene. J Biol Chem 274: 26071-8 https://doi.org/10.1074/jbc.274.37.26071

26. YU GW, CHEN J, CHEN YY, ZHENG MZ, SHEN YL 2012 Heat-shock protein 90-dependent translocation of Akt to mitochondria mediates insulin-like growth factor 1-induced protection of rat hearts under hypothermic preservation. Chin J Pathophysiol 28: $1773-8$

27. YUAN R, TSAIH SW, PETKOVA SB, MARIN DE EVSIKOVA C, XING S, MARION MA, ET al. 2009 Aging in inbred strains of mice: study design and interim report on median lifespans and circulating IGF1 levels. Aging Cell 8: 277-87 https://doi.org/10.1111/j.1474-9726.2009.00478.x

28. CHISALITA SI, DAHLSTROM U, ARNQVIST HJ, ALEHAGEN U 2011 Increased IGF1 levels in relation to heart failure and cardiovascular mortality in an elderly population: impact of ACE inhibitors. Eur J Endocrinol 165: 891-8 https://doi.org/10.1530/EJE-11-0584

29. BOQUIST S, RUOTOLO G, SKOGLUND-ANDERSSON C, TANG R, BJÖRKEGREN J, BOND MG, et al. 2008 Correlation of serum IGF-I and IGFBP-1 and -3 to cardiovascular risk indicators and early carotid atherosclerosis in healthy middle-aged men. Clin Endocrinol (Oxf) 68: 51-8

https://doi.org/10.1111/j.1365-2265.2007.02998.x

30. SEVERS NJ, BRUCE AF, DUPONT E, ROTHERY S 2008 Remodelling of gap junctions and connexin expression in diseased myocardium. Cardiovasc Res 80: 9-19 https://doi.org/10.1093/cvr/cvn133

31. GUERRERO PA, SCHUESSLER RB, DAVIS LM, BEYER EC, JOHNSON CM, YAMADA KA, et al. 1997 Slow ventricular conduction in mice heterozygous for a connexin 43 null mutation. J Clin Invest 99: 1991-8 https://doi.org/10.1172/JCI119367

32. KREUZBERG MM, SCHRICKEL JW, GHANEM A, KIM JS, DEGEN J, JANSSEN-BIENHOLD U, et al. 2006 Connexin 30.2 containing gap junction channels decelerate impulse propagation through the atrioventricular node. Proc Natl Acad Sci U S A 103: 5959-64 https://doi.org/10.1073/pnas.0508512103

33. ALCOLEA S, JARRY-GUICHARD T, DE BAKKER J, GONZÀLEZ D, LAMERS W, COPPEN S, et al. 2004 Replacement of connexin 40 by connexin 45 in the mouse: impact on cardiac electrical conduction. Circ Res 94: 100-9 https://doi.org/10.1161/01.RES.0000108261.67979.2A

34. AI Z, FISCHER A, SPRAY DC, BROWN AM, FISHMAN GI 2000 Wnt-1 regulation of connexin 43 in cardiac myocytes. J Clin Invest 105: 161-71 https://doi.org/10.1172/JCI7798

35. PAUL M, WICHTER T, GERSS J, ARPS V, SCHULZE-BAHR E, ROBENEK H, et al. 2013 Connexin expression patterns in arrhythmogenic right ventricular cardiomyopathy. Am J Cardiol 111: 1488-95 https://doi.org/10.1016/j.amjcard.2013.01.299

36. MA Y, LIU GX, DONG HW 2008 Application of immunohistochemistry of VEGF in the diagnosis of sudden cardiac death. J Jining Med Coll 31: 231-2

37. ZHU BL, TANAKA S, ISHIKAWA T, ZHAO D, LI DR, MICHIUE T, et al. 2008 Forensic pathological investigation of myocardial hypoxia-inducible factor- $1 \alpha$, erythropoietin and vascular endothelial growth factor in cardiac death. Leg Med (Tokyo) 10: 11-9 https://doi.org/10.1016/j.legalmed.2007.06.002

38. NGUYÊN-TRÂN VT, KUBALAK SW, MINAMISAWA S, FISET C, WOLLERT KC, BROWN AB, et al. 2000 A novel genetic pathway for sudden cardiac death via defects in the transition between ventricular and conduction system cell lineages. Cell 102: 671-82 https://doi.org/10.1016/S0092-8674(00)00089-1

39. TOKO H, MINAMINO T, KOMURO I 2008 Role of heat shock transcriptional factor 1 and heat shock proteins in cardiac hypertrophy. Trends Cardiovasc Med. 18: 88-93 https://doi.org/10.1016/j.tcm.2008.01.003 
40. SOMERS JR, BECK PL, LEES-MILLER JP, ROACH D, LI Y, GUO J, et al. 2008 iNOS in cardiac myocytes plays a critical role in death in a murine model of hypertrophy induced by calcineurin. Am J Physiol Heart Circ Physiol. 295: H1122-31 https://doi.org/10.1152/ajpheart.00386.2008

41. NOSEWORTHY PA, NEWTON-CHEH C. 2008 Genetic determinants of sudden cardiac death. Circulation. 118: 1854-63 https://doi.org/10.1161/CIRCULATIONAHA.108.783654

42. ABBATE A, BIONDI-ZOCCAI GG, BALDI A. 2002 Pathophysiologic role of myocardial apoptosis in post-infarction left ventricular remodeling. J Cell Physiol. 193: 145-53 https://doi.org/10.1002/jcp.10174

43. SOVARI AA, IRAVANIAN S, DOLMATOVA E, JIAO Z, LIU H, ZANDIEH S, et al. 2011 Inhibition of c-Src tyrosine kinase prevents angiotensin II-mediated connexin- 43 remodeling and sudden cardiac death. J Am Coll Cardiol. 58: 2332-9 https://doi.org/10.1016/j.jacc.2011.07.048

44. KEDIA R, SAEED M. 2012 Implantable cardioverter-defibrillators: indications and unresolved issues. Tex Heart Inst J. 39: 335- 41

45. SINHA AM, SCHMIDT M, MARSCHANG H, GUTLEBEN K, RITSCHER G, BRACHMANN J, et al. 2009 Role of left ventricular scar and Purkinje-like potentials during mapping and ablation of ventricular fibrillation in dilated cardiomyopathy. Pac- ing Clin Electrophysiol. 32: 286-90

https://doi.org/10.1111/j.1540-8159.2008.02233.x

46. YUAN SM 2014 Anomalous origin of coronary artery: taxonomy and clinical implication. Rev Bras Cir Cardiovasc. 29: 622-9 https://doi.org/10.5935/1678-9741.20140109

47. VASEGHI M, SHIVKUMAR K 2008 The role of the autonomic nervous system in sudden cardiac death. Prog Cardiovasc Dis. 50: 404-419 doi: 10.1016/j.pcad.2008.01.003.

48. PIERONI M, SMALDONE C, BELLOCCI F. Myocarditis presenting with ventricular arrhythmias: role of electroanatomical mapping-guided endomyocardial biopsy in differential diagnosis. http://cdn.intechopen.com/pdfs-wm/21894.pdf. Accessed on June 26, 2015.

49. STROM M, WANX, POELZING S, FICKER E, ROSENBAUM DS. 2010 Gap junction heterogeneity as mechanism for electrophysiologically distinct properties across the ventricular wall. Am J Physiol Heart Circ Physiol. 298: H787-94 https://doi.org/10.1152/ajpheart.00887.2009

50. NAKAMURA R, EGASHIRA K, MACHIDA Y, HAYASHIDANI S, TAKEYA M, UTSUMI H, et al. 2002 Probucol attenuates left ventricular dysfunction and remodeling in tachycardiainduced heart failure: roles of oxidative stress and inflammation. Circulation. 106: 362-7 https://doi.org/10.1161/01.CIR.0000021430.04195.51 